Marlena Robakowska ${ }^{1}$

Anna Tyrańska-Fobke ${ }^{2}$

Maciej Walkiewicz ${ }^{3}$

Małgorzata Tartas ${ }^{3}$

\title{
ADAPTIVE AND MALADAPTIVE PERFECTIONISM, AND PROFESSIONAL BURNOUT AMONG MEDICAL LABORATORY SCIENTISTS
}

\author{
Medical University of Gdańsk, Gdańsk, Poland \\ ${ }^{1}$ Department of Public Health and Social Medicine \\ ${ }^{2}$ 2nd Department of Radiology \\ ${ }^{3}$ Faculty of Psychology
}

\begin{abstract}
Background: The goal of this paper is to verify the correlations between adaptive and maladaptive perfectionism and the selected demographic and job characteristics vs. professional burnout among medical laboratory scientists in Poland. Material and Methods: The study group consisted of 166 laboratory scientists. The Polish Adaptive and Maladaptive Perfectionism Questionnaire (Szczucka) was used for testing perfectionism. The Oldenburg Burnout Inventory was used for examining burnout syndrome. Results: Adaptive perfectionism was positively and maladaptive perfectionism was negatively correlated with both aspects of professional burnout: the disengagement from work and exhaustion. What is more, maladaptive perfectionism was correlated negatively with age and work experience. People in relationships have a higher level of disengagement and a higher level of exhaustion than single ones. The results of hierarchical regression analyses have revealed, after having controlled selected demographic and job factors, that a significant predictor of disengagement is the high level of adaptive perfectionism and low level of maladaptive perfectionism. In addition, a significant predictor of high level of exhaustion is the low level of maladaptive perfectionism. Conclusions: Professional burnout among medical laboratory scientists is of a specific nature. The "healthier" perfectionism they reveal, the higher level of burnout they present. In this profession, lower risk of burnout is represented by those who are characterized by the lack of confidence in the quality of their actions and a negative reaction to their own imperfections associated with imposed social obligation to be perfect. The individuals pursuing their internal high standards experience burnout faster. Med Pr 2018;69(3):253-260
\end{abstract}

Key words: burnout, adaptive perfectionism, maladaptive perfectionism, laboratory scientists, disengagement, exhaustion

Corresponding author: Anna Tyrańska-Fobke, Medical University of Gdańsk, 2nd Department of Radiology,

Smoluchowskiego 17, 80-214 Gdańsk, Poland, e-mail: anka.tyranska@gumed.edu.pl

Received: May 11, 2017, accepted: November 7, 2017

\section{INTRODUCTION}

The goal of this paper is to verify the correlations between adaptive and maladaptive perfectionism and the selected demographic and job characteristics versus professional burnout among medical laboratory scientists in Poland.

\section{Adaptive and maladaptive perfectionism}

Nowadays perfectionism is a factor that appears more and more often in the research concerning professional burnout [1]. The suggested model distinguishes perfectionistic striving vs. perfectionistic concerns [2]. Perfectionistic striving is also known as adaptive perfectionism that "is normal, healthy and aimed at personal achievements and goals." People of this personality type are focused on their high personal standards as well as strive for perfection and achievements.

"Healthy perfectionists" seek to achieve perfect standards in their activities and feel comfortable with these demands. Perfectionistic syndromes are known as maladaptive perfectionism, "neurotic and socially induced." The characteristics of this type is prevailing criticisms of one's own performance and achievements, the fear of flaws and negative responses to failures, as well as strong feeling of social pressure to be perfect. "Neurotic perfectionists" usually endlessly try to improve effects of their work which they are able to accept as long as it is absolutely flawless. They treat each single mistake as a failure. They are rarely self-satisfied with their achievements and often feel discouraged and inferior to others. The above forms of perfectionism may 
be correlated and this means that an individual can obtain high results in both of them [3].

The analysis of literature review implies that maladaptive perfectionism is connected with professional burnout. However, adaptive perfectionism contributes to increased engagement $[4,5]$. The literature on the subject implies that the above mechanisms depend on an individual approach to dealing with stress. Maladaptive perfectionism is related to emotion-focused coping. Thus adaptive perfectionism correlates positively with problem-focused coping [3].

\section{Medical laboratory scientists as healthcare professionals}

Most of doctor's diagnoses are based on laboratory tests and imaging examinations which are mostly performed by medical laboratory scientists. According to the provision of the Act of 27 July 2001 on laboratory diagnostic [6], a medical laboratory scientist is a person performing laboratory work in the medical field. They are responsible for undertaking technical and methodological analyses and studies by sampling, processing, reporting, assessing and evaluating measurements and findings. These professionals may be employed at various laboratories working for hospitals, health-care centers, pharmaceutical companies, forensic labs or research centers.

A medical laboratory scientist is a university graduate of the faculty of the Medical Analytics or another equivalent academic degree, i.e., veterinary medicine, biology, pharmaceutic science or chemistry, supplemented by corresponding post-graduate studies. Medical laboratory scientists are also graduates of the faculty of general medicine or medical analytics, laboratory or microbiology diagnostics. Twenty-five years ago in Poland, before the faculties of the Medical Analytics started as separate faculties at medical universities, laboratory diagnostics had been performed by doctors, pharmacists, chemists and biologists. At present, the vast majority of graduates of the Medical Analytics are employed at laboratories. An interesting fact is that a similar system of obtaining qualification in this field may only be found in Hungary and Croatia.

The burdens consequent to this profession are connected with responsibility for a patient's health and life and conditions specific for it: the body position during medical examinations with the use of medical appliances and equipment, the lab microclimate, ambient noise, contact with chemical substances, radioactivity or infective materials.
It seems that medical laboratory scientists' work in comparison with other medical professionals is very specific. If they want to achieve a good reproducibility of testing results, they have to strictly obey the prescribed procedures, instructions, regulations and rules. This means the field for their own creativity and innovation is relatively limited. A medical laboratory scientist must be very precise and accurate. One may believe that this kind of job favors individuals who are submissive and follow the accepted standards.

\section{Professional burnout}

The concept of professional burnout was first called by Freudenberg in 1974 [7]. At the beginning, the phenomenon was described as a psychological syndrome of 3 symptoms: emotional exhaustion, depersonalization and reduced sense of personal accomplishment [8].

Initially, it was attributed to representatives of social services, i.e., doctors, nurses, teachers, due to the emotionally exhausting relationship between those who help and those who need their support. At the beginning of the 90s professional burnout syndrome was also observed in other professionals who did not have such intense emotional relationships with others (e.g., programmers, managers) [9]. Consequently, the concept of this syndrome was broadened, more universal and was applied to other professionals.

At present, it is thought that key factors for developing professional burnout syndrome are: too demanding job, insufficient personal resources as well as some personal features that may modify perception and reactions towards job demands, perceiving and using personal resources [10]. Moreover, understanding separate syndromes of professional burnout has been changed as well. Bifactor model is commonly discussed now. It is based on "exhaustion" that means not only energy decrease but also limited cognitive abilities and "disengagement from work" that implies negative approach towards any things and tasks connected with it. It is worth noticing that that the component of "reduced sense of personal accomplishment" appears independently at later stages of professional burnout and this may be considered to be a consequence of the phenomenon rather than its axial element $[11,12]$.

\section{Professional burnout, perfectionism and medical professionals}

There are no studies concerning correlation between perfectionism and professional burnout among medical laboratory scientists. However, there is some data 
on this subject in relation to nurses. An interesting Polish research shows that maladaptive perfectionism is a predictor for both intensive exhaustion and disengagement from work. On the other hand, adaptive perfectionism is of "protective nature, preserving engagement in work and counteracting exhaustion" [1]. It has also been presumed that the above effects will appear after having controlled the influence of selected demographic and occupational factors. Adaptive perfectionism correlates positively with the age and professional experience. What is more, marital status of the respondents in the research is significantly correlated with both aspects of professional burnout. Single people are less engaged in their professional duties than these who are in relationships. Divorced people display a significantly higher level of exhaustion than these who share their life with others [1].

The above data is going to serve as a matrix that the authors of this work would like to develop and possibly, start a discussion. Even if the results obtained by Włodarczyk and Obacz [1] are related to the other group of medical professionals, they are treated by the authors of this work as a model that implies 2 main hypotheses:

H1: Adaptive perfectionism of medical laboratory scientists is negatively related to professional burnout (in its segments, that is: exhaustion and disengagement from work). However, maladaptive perfectionism is related positively to them.

$\mathrm{H} 2$ : Adaptive perfectionism is positively related with the age and professional experience and maladaptive perfectionism is related negatively to them.

There are some additional hypotheses:

H3: Professional burnout (in its segments, that is: exhaustion and disengagement from work) is also related with marital status. Single people show a higher level of professional burnout.

H4: Professional burnout may be predicted on the basis of: demographic factors (age, marital status), the length of professional experience and the type of perfectionism.

\section{MATERIAL AND METHODS}

\section{Research procedures}

The respondents were invited to take part in an anonymous survey through information on the website of The National Chamber of Medical Laboratory Scientists. Each interested medical laboratory scientist in the country could take part in the survey. The respondents could complete an anonymous form placed in the
Internet at any time convenient to them. It was not necessary to $\log$ in, register an account or to reveal personal data.

The only condition to be included in the examined sample was completing 2 questionnaires and a respondent's information table. The first questionnaire was completed by 182 respondents, and the second by 229 . Only completely filled records (2 questionnaires and a respondent's information table) were taken into account. The applied formula did not concern those who refused to participate in the survey or gave up filling it.

This research programme was conducted in accordance with the guidelines of the Bioethics Committee of the Medical University of Gdańsk, Poland, which reviewed and approved the project (by decision NKBBN/ 487/2016-2017).

\section{Material}

One hundred sixty-six medical laboratory scientists from a number of regions of Poland were qualified for the research. The mean $(M)$ age was $36.6 \pm 10.1$ years old, $89 \%$ of females, $75 \%$ in relationships, $25 \%$ singles, $0.6 \%$ widowed.

Professional experience: $35 \%$ worked in the profession up to 5 years, $25 \%-6-10$ years, $12 \%-11-15$ years, $7 \%-16-20$ years and $26-30$ years, $8 \%-21-25$ years, $7 \%$ - over 31 years. Education: 59\% - university graduates, 33\% - university graduates with specialization, 8\% - Doctors of Philosophy (Ph.D.) or Ph.D. with specialization. Employment in private institutions vs. public ones declared $40 \%$ vs. $60 \%$ of the respondents.

\section{Methods \\ Perfectionism}

The Polish Adaptive and Maladaptive Perfectionism Questionnaire by Szczucka was used for evaluating perfectionism [12]. The questionnaire consists of 35 statements concerning personal characteristics and traits. The respondents are asked to present their agreement or disagreement by using the scale of 1-7 (from "absolutely disagree" to "absolutely agree") [12].

\section{Professional burnout}

The Polish version of the Oldenburg Burnout Inventory (OLBI) by Demerouti et al. [13] and adapted by Cieślak was used for measuring the concept of burnout [14]. The questionnaire consists of 16 statements concerning the respondent's attitude to their work in relation to their feelings and examines both exhaustion and disengagement from work. The respondents 
express their agreement or disagreement by using the scale of 1-4 (from "agree" to "disagree"). According to the instructions, for some questions the results were calculated by recoding answers. The higher the result, the higher level of burnout $[13,14]$.

Moreover, the respondents were asked to complete a questionnaire that consisted 6 questions about some demographic data (age, sex, marital status) and professional data (experience, education level, type of employment).

\section{Statistical analysis}

The correlation analyses were applied to establish the relationship between explanatory variables and professional burnout for quantitative variables such as: age and work experience and 2 types of perfectionism (adaptive and maladaptive). The analysis of variance (ANOVA) was used for establishing the relationship between marital status and professional burnout. The model of hierarchical analysis of regression was applied for establishing predictors of professional burnout. This model was tested separately for both types of perfectionism (adaptive and maladaptive perfectionism).

Analyzed predictors were entered in 3 segments. The first one included demographic variables such as age and marital status (2-category variables: 1 - single, 2 - in relationship). In the second one there were variables related to work experience (7-category variables: $1-5$ years, $6-10$ years, $11-15$ years, $16-20$ years, $21-25$ years, $26-30$ years, $\geq 31$ years). Two types of perfectionism: adaptive and maladaptive perfectionism were included in the third segment. SPSS software was used.

\section{RESULTS}

\section{Relationship between explanatory variables and professional burnout}

The presented results of correlation analyses for quantitative variables (Table 1) show that adaptive perfectionism correlates positively with professional burnout (in its segments, that is exhaustion and disengagement from work) and maladaptive perfectionism correlates negatively with professional burnout (in its segments, that is exhaustion and disengagement from work).What is more, maladaptive perfectionism correlates negatively with age and work experience. No correlation between professional burnout and work experience was reported.

The analysis of variance (ANOVA) implies statistically significant relationship of the respondents' marital status with both aspects of burnout, that is: exhaustion and disengagement from work (Table 2). Single persons were more engaged in their work than those living in relationships and their level of exhaustion was significantly lower.

\section{Results of analysis of regression}

The Table 3 shows the predictors of disengagement from work. Among demographic variables applied in the first regression model - age and marital status turned out to be statistically significant. The predictors of more disengagement from work were: advanced age $(\beta=0.137$, $\mathrm{t}=1.838)$ and living in a relationship $(\beta=0.303$, $\mathrm{t}=3.930$ ). Upon adding the regression of working experience to the equation - model 2 turned out to be

Table 1. Correlation between adaptive and maladaptive perfectionism and the selected demographic and job characteristics vs. professional burnout among medical laboratory scientists $(\mathrm{N}=166)$ in Poland

\begin{tabular}{|c|c|c|c|c|c|c|c|}
\hline \multirow[b]{2}{*}{ Variable } & \multirow[b]{2}{*}{ M } & \multirow[b]{2}{*}{$\mathrm{SD}$} & \multicolumn{5}{|c|}{ Pearson's correlation coefficient } \\
\hline & & & age & working time & $\begin{array}{c}\text { adaptive } \\
\text { perfectionism } \\
(\mathrm{PAD})\end{array}$ & $\begin{array}{l}\text { maladaptive } \\
\text { perfectionism } \\
\quad(\mathrm{PAD})\end{array}$ & $\begin{array}{l}\text { disengagement } \\
\text { from work } \\
(\mathrm{OLBI})\end{array}$ \\
\hline Age & 36.62 & 10.10 & - & - & & & \\
\hline Working time & - & - & - & - & & & \\
\hline Adaptive perfectionism (PAD) & 70.93 & 11.50 & 0.110 & 0.137 & - & & \\
\hline Maladaptive perfectionism (PAD) & 63.55 & 23.24 & $-0.194^{* *}$ & $-0.198^{\star *}$ & $-0.259^{* * *}$ & - & \\
\hline Disengagement from work (OLBI) & 22.30 & 5.42 & 0.121 & 0.121 & $0.404^{* * *}$ & $-0.362^{* * *}$ & - \\
\hline Exhaustion (OLBI) & 22.09 & 5.10 & 0.110 & -0.028 & $0.267^{\star * *}$ & $-0.432^{* * *}$ & $0.687^{\star \star *}$ \\
\hline
\end{tabular}

PAD - Polish Adaptive and Maladaptive Perfectionism Questionnaire [12], OLBI - Oldenburg Burnout Inventory [14].

$\mathrm{M}-$ mean, $\mathrm{SD}-$ standard deviation.

${ }^{* *} \mathrm{p}<0.01,{ }^{* * *} \mathrm{p}<0.001$. 
Table 2. Marital status vs. professional burnout among medical laboratory scientists $\left(\mathrm{N}=166^{\star}\right)$ in Poland

\begin{tabular}{lccc}
\hline \multicolumn{1}{c}{ Variable } & $\mathrm{M}$ & $\mathrm{SD}$ & $\mathrm{F}$ \\
\hline Exhaustion & & & \\
single $(\mathrm{N}=41)$ & 19.7561 & 5.10284 & \\
married, living with & 22.8710 & 4.90059 & 12.196 \\
partner (N = 124) & & & \\
Disengagement from work & 19.5854 & 5.20084 & \\
single (N = 41) & 23.2097 & 5.22700 & 14.850 \\
married, living with & & \\
partner (N = 124) & & & \\
\hline
\end{tabular}

* One person, who as a marital status pointed "widow/widower," was excluded from the analysis.

$\mathrm{M}$ - mean, SD - standard deviation, F - F statistics.

Table 3. Hierarchical regression analysis for a dependent variable - disengagement from work among medical laboratory scientists $(\mathrm{N}=166)$ in Poland

\begin{tabular}{|c|c|c|c|c|c|c|c|c|c|}
\hline Variable & \multicolumn{3}{|c|}{ Model 1} & \multicolumn{3}{|c|}{ Model 2} & \multicolumn{3}{|c|}{ Model 3} \\
\hline \multicolumn{10}{|c|}{ Demographic factors } \\
\hline age & 0.009 & 0.137 & $1.838^{*}$ & 0.027 & 0.405 & 1.378 & 0.038 & 0.558 & $2.122^{* * *}$ \\
\hline marital status & 0.475 & 0.303 & $3.930^{* *}$ & 0.456 & 0.291 & $3.722^{* *}$ & 0.316 & 0.202 & $2.784^{* * *}$ \\
\hline working time & & & & -0.111 & -0.315 & -1.060 & -0.173 & -0.491 & $-1.847^{\star}$ \\
\hline \multicolumn{10}{|l|}{ Perfectionism } \\
\hline $\begin{array}{l}\text { adaptive } \\
\text { perfectionism }\end{array}$ & & & & & & & 0.022 & 0.380 & $5.225^{\star *}$ \\
\hline $\begin{array}{l}\text { maladaptive } \\
\text { perfectionism }\end{array}$ & & & & & & & -0.006 & -0.206 & $-2.778^{* * *}$ \\
\hline$\Delta \mathrm{R}^{2}$ & & $0.116^{* *}$ & & & 0.010 & & & $0.193^{* *}$ & \\
\hline
\end{tabular}

F - F statistics, $R^{2}$ - explained variance, $\Delta \mathrm{R}^{2}$ - addition of explained variance, $\mathrm{B}$ - non-standardized regression coefficient, $\beta$ - standardized regression coefficient.

Model 1 - first regression model (demographic variables such as age and marital status (2-category variables: 1 - single, 2 - in relationship)).

Model 2 - second regression model (variables related to work experience (7-category variables: 1-5 years, 6-10 years, 11-15 years, 16-20 years, 21-25 years, 26-30 years, $\geq 31$ years))

Model 3 - third regression model (2 types of perfectionism: adaptive and maladaptive perfectionism).

${ }^{*} \mathrm{p}<0.05,{ }^{* *} \mathrm{p}<0.01,{ }^{* * *} \mathrm{p}<0.001$.

$\wedge \mathrm{p}>0.05$.

statistically insignificant. Upon adding the perfectionism variables in the final model (model 3$)$ - age $(\beta=0.558$, $\mathrm{t}=2.122)$ and marital status $(\beta=0.202, \mathrm{t}=2.784)$ preserved their statistical significance.

Other statistically significant predictors of disengagement from work such as: work experience $(\beta=0.491$, $t=1.847)$ - the shorter, the higher level of disengagement from work; adaptive perfectionism $(\beta=0.380$, $t=5.225)$ - the higher, the higher level of disengagement from work; and maladaptive perfectionism ( $\beta=0.206$, $t=2.778)$ - the lower, the higher level of disengagement from work.

To sum up, the considered demographic variables (model 1) allowed to explain 12\% of the cases of disengagement from work. Adding 2 levels of perfectionism to the regression model (model 3), contributed to the increase of the explanatory variable by another $19 \%$. 
Table 4. Hierarchical regression analysis for a dependent variable - exhaustion among medical laboratory scientists $(\mathrm{N}=166)$ in Poland

\begin{tabular}{|c|c|c|c|c|c|c|c|c|c|}
\hline \multirow{2}{*}{ Variable } & \multicolumn{3}{|c|}{ Model 1} & \multicolumn{3}{|c|}{ Model 2} & \multicolumn{3}{|c|}{ Model 3} \\
\hline & B & $\beta$ & $\mathrm{t}$ & B & $\beta$ & $\mathrm{t}$ & B & $\beta$ & $\mathrm{t}$ \\
\hline \multicolumn{10}{|l|}{ Demographic factors } \\
\hline age & 0.000 & 0.006 & 0.080 & 0.019 & 0.299 & 1.002 & 0.024 & 0.381 & 1.407 \\
\hline marital status & 0.437 & 0.296 & $3.779^{* *}$ & 0.437 & 0.299 & $3.733^{* *}$ & 0.257 & 0.174 & $2.334^{\wedge}$ \\
\hline \multicolumn{10}{|l|}{ Occupational factors } \\
\hline working time & & & & -0.100 & -0.302 & -1.002 & -0.137 & -0.412 & -1.507 \\
\hline \multicolumn{10}{|l|}{ Perfectionism } \\
\hline adaptive perfectionism & & & & & & & 0.011 & 0.192 & $2.562^{\wedge}$ \\
\hline maladaptive perfectionism & & & & & & & -0.010 & -0.373 & $-4.879^{* *}$ \\
\hline $\mathrm{F}$ & & $5.048^{\wedge}$ & & & 2.940 & & & $7.500^{\star *}$ & \\
\hline $\mathrm{R}^{2}$ & & $0.069 \wedge$ & & & 0.066 & & & $0.241^{* *}$ & \\
\hline$\Delta \mathrm{R}^{2}$ & & $0.086^{\wedge}$ & & & 0.014 & & & $0.177^{\star *}$ & \\
\hline
\end{tabular}

Abbreviations and explanations as in Table 3.

The Table 4 shows the results of the similar regression analysis for exhaustion. The Model 1, including demographic data, was statistically insignificant. Upon adding the work experience variables - the model 2 also appeared to be statistically insignificant. By adding 2 levels of perfectionism to the regression model (model 3), 24\% cases of exhaustion were explained. However, a significant predictor of exhaustion is only maladaptive perfectionism - the higher, the lower level of exhaustion $(\beta=0.373, t=4.879)$. Thus, adaptive perfectionism, in this case, is significant only at the level of statistical tendency.

\section{DISCUSSION}

The aim of the discussed research is to find the relationship between perfectionism and the selected demographic and job characteristics vs. professional burnout among medical laboratory scientists in Poland. The concept of 2 aspects of perfectionism has been adopted for the purpose of this work, i.e., adaptive (healthy) and maladaptive (unhealthy) [4,12]. Moreover, a bifactor model of professional burnout has been considered comprising exhaustion and disengagement from work $[11,13,14]$.

It has appeared that both aspects of professional burnout: exhaustion and disengagement from work are positively correlated with adaptive perfectionism and negatively with maladaptive perfectionism. Conducted analyses of hierarchical regression have confirmed that when some demographic and professional factors are taken into account, the high level of adaptive perfectionism but the low level of maladaptive perfectionism constitute a significant predictor of disengagement from work. A significant predictor of the high level of exhaustion is the low level of maladaptive perfectionism.

These findings seem to question the appropriateness of rigid interpretation of perfectionism as adaptive and maladaptive [2-5]. In the case of medical laboratory scientists the situation is contrary to the results of the research that has been presented before, that is: individuals displaying maladaptive perfectionism are less likely to develop professional burnout. It may be consequent to the specific character and some predispositions to their job. Individuals having a specific constellation of personal traits choose this type of job or they can only do it for a longer period of time.

Adapting to such an accurate job might be easier for people who display the higher level of the fear of making mistakes and react to them in a negative way; people who are in doubt about their performance, constantly trying to improve their results and with stronger social pressure to be perfect. They are influenced by the pressure to be perfect, which comes from outside, contrary to "healthy perfectionists" who pursue perfection and want to be perfect themselves. The first ones search for jobs in demanding environment. A possible explanation is that the existing procedures, rules, regulations, tools as such become the expected sense of their work. Highly formal professional demands are correspondent 
to rigorous self-assessment criteria and expected critical feedback from the outside. Thus, in such cases the process burnout gets slower.

On the other hand, medical laboratory scientists with a high level of adaptive perfectionism experience burnout earlier, as they tend to be more interested in their self-development and obtaining job satisfaction. In the long term, their "healthy/adaptive" strive for professional achievements, which in the case of other jobs could be a reason for obtaining positive self-esteem, may absorb too much available resources such as time or energy.

Moreover, job expectations may be associated with giving up creativity and result in frustration and exhaustion. In the tested group, maladaptive perfectionism was linked negatively with the age and work experience. It is probable that these who work as medical laboratory scientists, with the passage of time, change their psychosocial functioning for more "neurotic" to adapt to challenges at work. Therefore, the possibility of their professional burnout may increase with the age and work experience.

Similarly, individuals in relationships show a significantly higher level of disengagement from work and exhaustion than single ones. This result is not consistent with the theory of social support. In the case of medical laboratory scientists, this effect broadens the concept of one of the basic theories in the health psychology. It is believed that social support is a basic source of protecting us against negative consequences of job stress $[15,16]$. A possible explanation is that laboratory scientists perceive living in the relationship negatively, more as a burden than support. It may be thought that they perceive contacts with other people as potentially controlling and assessing rather than supportive. This interpretive hypothesis itself makes an interesting subject for further research in the future.

This work has some limitations and some restraint should be called for in order to draw general conclusions. The research has been of a cross-sectional study and concerned a selected group of demographic and professional factors. The list of variables is worth expanding in further research. Another limitation is a disparity in gender of respondents (most of them are females) and in their marital status (most of them live in relationships). That is why the obtained results should be interpreted vaguely and carefully as far as the whole population of medical laboratory scientists is concerned.

We are of the opinion that for better understanding of specificity of professional burnout among medical laboratory scientists such factors as the age, work experience, and marital status demand deeper insight.

\section{CONCLUSIONS}

Professional burnout among medical laboratory scientists is of special nature. The "healthier" perfectionism is displayed by the respondents, the higher level of professional burnout they obtain. In this profession, the individuals who are in doubt about their performance are less likely to suffer from burnout. They react more negatively to their imperfections consequent to the need to be perfect that is imposed by their environment (e.g., other people, procedures, standards).

It seems that this problem should be explored in a more systematic and deeper way. Appropriate methods of intervention should be worked out in order to minimize the risk of professional burnout among medical laboratory scientists. In the light of obtained results, the basic thing would be the assumption of psychological profile of the future laboratory scientists for proofing interpretive hypotheses concerning intermediate role of perfectionism in developing burnout.

\section{REFERENCES}

1. Włodarczyk D, Obacz W. [Perfectionism, selected demographic and job characteristics as predictors of burnout in operating suite nurses]. Med Pr. 2013;64(6):761-73, http:// dx.doi.org/10.13075/mp.5893.2013.0071. Polish.

2. Stoeber J, Rennert D. Perfectionism in school teachers: Relations with stress appraisals, coping styles, and burnout. Anxiety Stress Coping. 2008;21(1):37-53, https://doi. org/10.1080/10615800701742461.

3. Stoeber J, Janssen D. Perfectionism and coping with daily failures: Positive reframing helps achieve satisfaction at the end of the day. Anxiety Stress Coping. 2011;24(5):477-97, https://doi.org/10.1080/10615806.2011.5629.

4. Zang Y, Gan Y, Cham H. Perfectionism, academic burnout and engagement among Chinese college students: A structural equation modeling analyses. Pers Individ Differ. 2007;43(6):1529-40, https://doi.org/10.1016/j.paid.2007. 04.010 .

5. Tashman LS, Tennenbaum G, Eklund R. The effect of perceived stress on the relationships between perfectionism and burnout in coaches. Anxiety Stress Coping. 2010;23(2): 195-212, https://doi.org/10.1080/10615800802629922.

6. [The Decree issued by the Minister of Labor and Social Policy of June 23, 2014 on mazimum admissible concentration and maximum admissible intensity values for agents 
harmful to human health in the work environment. Off J Laws 2014, No. 0, item 817]. Polish.

7. Freudenberger HJ. Staff burn-out. J Soc Issues. 1974;30 (1):159-65, https://doi.org/10.1111/j.1540-4560.1974.tb0 0706.x.

8. Maslach C, Schaufelli WB, Leiter MP. Job burnout. Ann Rev Psychol. 2001;52:397-422, https://doi.org/10.1146/annurev.psych.52.1.397.

9. Demerouti E, Bakker AB, Nachreiner F, Schaufeli WB. The job demands-resources model of burnout. J Appl Psychol. 2001;86(3):499-512, https://doi.org/10.1037/00219010.86.3.499.

10. Bakker AB, Demerouti E. The Job Demands-Resources model: State of the art. J Manag Psychol. 2006;22(3):30928, https://doi.org/10.1108/02683940710733115.

11. Lee RT, Ashforth BE: A meta-analytic examination of correlates of the 3 dimensions of job burnout. J Appl Psychol. 1996;81(2):123-33, https://doi.org/10.1037/0021-90 10.81.2.123.

12. Szczucka K. [The Polish Adaptive and Maladaptive Perfectionism Questionnaire]. Psychol Spol. 2010;5(1(13)): 71-95. Polish.
13. Demerouti E, Bakker AB, Vardakou I, Kantas A. The convergent validity of 2 burnout instruments: A multitrait-multimethod analysis. Eur J Psychol Assess. 2003;19(1):12-23, https://doi.org/10.1027//1015-5759.19.1.12.

14. Baka $€$, Basińska BA. [Psychometric properties of the Polish version of the Oldenburg Burnout Inventory (OLBI)]. Med Pr. 2016;67(1):29-41, https://doi.org/10.13075/mp. 5893.00353. Polish.

15. Innstrand ST, Langballe EM, Espnes EA, Aasland OG, Falkum E. Personal vulnerability and work-home interaction: The effect of job performance-based self-esteem on work/home conflict and facilitation. Scand J Psychol. 2010;51(6):480-7, https://doi.org/10.1111/j.1467-9450.20 10.00816.x.

16. Innstrand ST. Positive and negative work-home interaction: An integrative model. In: Innstrand ST, editor. Health promotion - Theory and practice. Trondheim: Research Centre for Health Promotion and Resources HiST/ NTNU; 2012. p. 9-25.

This work is available in Open Access model and licensed under a Creative Commons Attribution-NonCommercial 3.0 Poland License - http://creativecommons.org/licenses/by-nc/3.0/pl/deed.en. 